\title{
ALEJANDRO FAURÉ, CRONISTA VISUAL DE LA SOCIEDAD CHILENA DE FINES DEL SIGLO XIX E INICIOS DEL SIGLO XX
}

\section{ALEJANDRO FAURÉ, VISUAL CHRONICLER OF CHILEAN SOCIETY OF THE LATE NINETEENTH CENTURY AND EARLY TWENTIETH CENTURY}

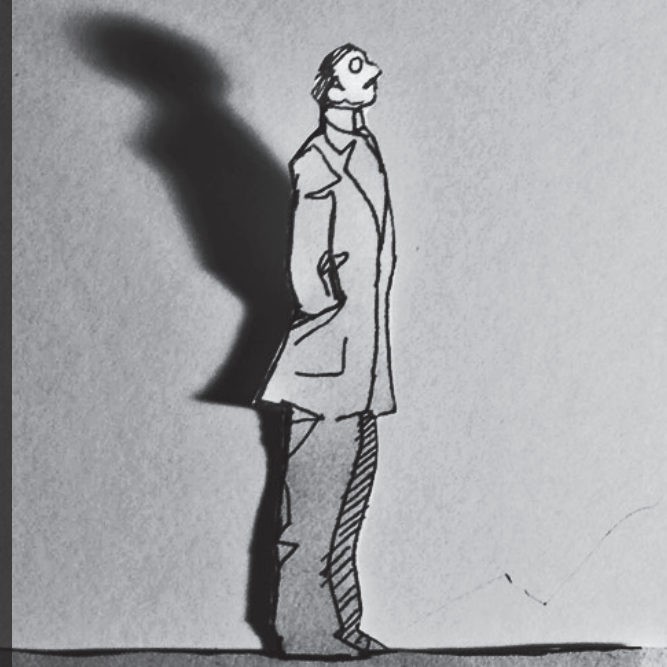

Por:

Mariana Muñoz ${ }^{1}$

Magister en Comunicación y Educación

Docente de la Universidad Gabriela Mistral Santiago de Chile

María Fernanda Villalobos ${ }^{2}$

Diseñadora de la Pontificia Universidad

Católica de Chile

Docente de Universidad de Chile y Universidad

Gabriela Mistral

Resumen: Alejandro Fauré Boyer fue un prolífico artista gráfico nacido en la ciudad de Valparaíso el 5 de mayo de 1865. Fue el menor de los hijos de un matrimonio de inmigrantes franceses. La cultura europea de su hogar, el oficio del padre y el carácter cosmopolita del puerto fueron las influencias que llevaron a Fauré a formarse en el rigor del trabajo, comenzando a los 15 años como dibujante en la Litografía Gillet, en Valparaíso. Posteriormente, se traslada con su madre a Santiago donde instala una oficina-taller para prestar sus servicios a la Imprenta y Encuadernación Barcelona, una importante empresa dedicada al desarrollo de numerosas publicaciones. Ahí Fauré desempeñó una amplia labor como dibujante y director artístico. Este artículo examina algunos pasajes claves de la historia intelectual de una de las figuras más influyentes del diseño, la ilustración y la gráfica en Chile. Para ello se ocupa de cuatro aspectos de su obra: la Ilustración y el diseño editorial, el humor gráfico, el desarrollo de avisos publicitarios y la tipografía y rotulación.

Palabras claves: Historia, ilustración, diseño gráfico. 


\begin{abstract}
Alejandro Fauré Boyer was a prolific graphic artist who was born in the city of Valparaiso on May 5, 1865. He was the youngest child of a marriage of French immigrants. The European culture of his home, his father's occupation and the cosmopolitan nature of the port were the influences that led Faure to form himself in the rigour of the work, beginning at the age of 15 as a draftsman in the Gillet Lithograph in Valparaiso. Later, he moved to Santiago with his mother where he installs an office-studio to provide services to the Printing and Binding Barcelona, an important company dedicated to the development of several publications. There, Fauré played an extensive role as illustrator and art director. This article examines some key passages of the intellectual history of one of the most influential figures of design, illustration and graphics in Chile. This addresses four aspects of his work: the illustration and editorial design, the graphic humor, the development of ads, and typography and lettering.
\end{abstract}

Keywords: History, illustration, graphic design.

\title{
1. Desde Europa
}

Alejandro Fauré Boyer fue un prolífico artista gráfico chileno descendiente de franceses. Sus padres, Paul Fauré y Josefina Boyer, deciden emigrar de Francia debido a la delicada situación del país. En aquel tiempo, producto de los constantes conflictos que aún se producían como parte de las consecuencias de la Revolución Francesa, además de las promesas de prosperidad en las noticias que llegaban acerca de la "fiebre del oro" en Norteamérica, deciden embarcarse rumbo al estado de Oregon, en Estados Unidos, junto a los tres hijos que ya tenían: Edouard, Paulina y Ernest. En aquellos años el viaje hacia las ciudades de la costa este de América se hacía por mar, en una ruta que tomaba varias semanas y que obligaba a pasar por el Estrecho de Magallanes. Es así como cuando el buque donde venía la familia Fauré Boyer recaló en el puerto chileno de Valparaíso, un amigo les recomendó que se quedaran ahí (a pesar de que el rumor entre los europeos decía que Chile era un país que "se lo tragaría el mar”), principalmente debido a que por la gran cantidad de bandidos y delincuentes que habría en el país del norte, no habría un ambiente apropiado para la crianza de sus hijos. Ante este panorama, deciden quedarse en esta ciudad y pasan a formar parte de la gran comunidad extranjera que llegó a nuestro país por su propia cuenta. ${ }^{3}$

\section{Ser hijo de inmigrantes europeos en Chile}

Instalados en Chile, nacen los últimos tres hijos de la familia: Eugenia, Enrique y Alejandro, el menor, quien nació el 5 de mayo de 1865. No existe información acerca de las actividades que Paul Fauré haya desarrollado para mantener a su familia; sin embargo se sabe que fue un pintor aficionado, dedicado a realizar copias de cuadros famosos por encargo. Seguramente este oficio y las horas dedicadas a él fueron claves en la vida del pequeño Alejandro y en su posterior interés en el dibujo. 
Dentro del imaginario que alimentó la cultura visual de Fauré es importante mencionar que no existía en Chile material didáctico ni educativo proyectado especialmente para los niños, sino que más bien había una "adultización" de ellos al no ser actores relevantes para el mundo editorial. Sin ir más lejos, el primer producto editorial dirigido a los niños que se editó en Chile fue la revista El Peneca, cuyo primer número se publicó recién el año 1908.

Dado el origen de su familia, naturalmente que una de las principales influencias en la formación de Fauré fue la cultura europea que vivió en su casa, no solamente en su educación consciente (la lengua materna, las costumbres culinarias y las relaciones familiares), sino que también en la formación de un imaginario que más tarde se verá retratado en su obra, sobre todo lo relativo a la gráfica victoriana, ${ }^{4}$ asociada a la Revolución Industrial: coronas de laureles, rosetas, medallas con rostros de personajes destacados y fábricas humeantes. Si esto resulta ser una consecuencia de su vida "puertas adentro", su vida "puertas afuera" en un puerto de carácter cosmopolita aporta a la conformación de otro imaginario, compuesto por los grandes navíos y los anhelos de viaje y aventuras en tierras vírgenes, propios de la era del maquinismo.
No sólo en cuanto a lo que los buques y barcos representaban, sino también todos los productos de consumo que llegaban a instalarse en un país "tercermundista", cuyas etiquetas resaltaban lo exótico, aludían al viaje y a la capacidad de la nuevas máquinas de cubrir grandes distancias en poco tiempo, cuyo humo ayudaba a la representación de la velocidad y el poder. Se puede afirmar, entonces, que este imaginario viene a ser una representación objetiva de la realidad, no así lo sucedido con el Art Nouveau, ${ }^{5}$ que ilustró el mundo desde la subjetividad, representando oníricamente lugares lejanos o personajes ensoñadores y que, como veremos más adelante, también está muy presente en la obra gráfica de Fauré.

Al mismo tiempo es importante señalar la alta valoración que todo "lo europeo" tenía en la sociedad chilena de aquel entonces. Por ejemplo, las primeras "casas de novedades" instaladas como grandes comercios en nuestro país pertenecieron a franceses o descendientes de franceses. Tal es el caso de Las Novedades Parisienses o Casa Muzard. Incluso la familia Fauré tuvo, ya a comienzos del siglo XX, su propia tienda, la Casa Fauré, a cargo de Ernesto Fauré Hemette (sobrino de Alejandro), donde vendían utensilios para el uso doméstico, muebles y objetos ornamentales y decorativos. Otro francés muy influyente en el puer to fue Félix Leblanc, personaje destacado por dos razones. La primera es que él junto a Mauricio Rugendas publicaron el libro Álbum de Trajes y Costumbres Chilenas. ${ }^{6}$ La segunda razón es que, además de ser propietario de un importante local de comercio dedicado a la fotografía en Valparaíso, publicó el Álbum Vistas de Valparaíso, edición que ilustra con fotografías el puerto en el que Fauré nació, creció y comenzó su quehacer artístico. 


\section{Artista gráfico}

Todo este ambiente e influencias en su entorno fue lo que llevó a Alejandro Fauré a formarse en el rigor del trabajo, comenzando a los 15 años como dibujante en la Litografía Gillet en el puerto de Valparaíso, donde se producían etiquetas y envases, en 1880. Esto resulta curioso, además de dar cuenta de su formación autodidacta, principalmente porque el dibujo como disciplina era abordado por los contemporáneos de Fauré a partir de estudios formales en la Academia de Pintura, vinculada a las Bellas Artes y no a la Artes Gráficas, consideradas por aquel entonces "artes menores". La impresión litográfica comenzó en Valparaíso por el año 1840 (año en que se publicó justamente el Álbum de Rugendas) y su importancia radica en que permitió producir imágenes propias, dibujadas e impresas en el país y no continuar dependiendo de las matrices usadas que llegaban del extranjero y que hasta entonces se utilizaban para imprimir los ornamentos o grabados que aparecían en los primeros impresos realizados en el país. En resumen, pese a la admiración por el estilo de los modelos culturales extranjeros, existía la posibilidad de producir imágenes con contenido local para que circularan en el medio nacional.

Fauré, como dibujante litográfico, no solamente tenía la destreza y la habilidad para dibujar con plumilla o lápiz, sino que también sabía hacer ese dibujo "reproducible". Es así como el artista, junto con producir excelentes piezas gráficas, fue diestro en la práctica del "transporte”, la etapa en la cadena de la producción gráfica donde se traspasaba el dibujo original a la piedra litográfica para poder imprimir copias en serie. Esto resulta destacable, y para Fauré debió haber sido un motivo de valorización en su medio, pues no era común que el propio dibujante realizara esa tarea, sino que había artesanos expertos para ello. La disciplina en su formación autodidacta llevó a Fauré no solamente a comprender el dibujo, sino que también la pintura y la acuarela (Revista Noticias Gráficas, 1912, n 114), los cuales desarrolla con un lenguaje muy similar al utilizado por el Art Nouveau. 
les diseñaba personajes; intentaba inculcarles el interés por el arte y la cultura, sin embargo él nunca tomó la pintura como una posibilidad de desarrollo profesional, sino que más bien la practicaba como un pasatiempo, al igual que su padre.

La época de Fauré en Santiago, donde se instala en la década de 1890, se reconoce como el tiempo en que este artista gráfico termina de consagrarse, al haber sido contratado por la Imprenta Barcelona, empresa que comenzó a funcionar el año 1891 en

Esto resulta curioso, porque se podría decir que los grandes artistas de ese movimiento en Europa, como el caso de Alphonse Mucha, Cherét y Toulouse-Lautrec, fueron contemporáneos a Fauré. Por otro lado, la información en aquellos años no circulaba tan rápidamente como ocurre hoy gracias a los nuevos medios de comunicación, por lo que el conocimiento de estos artistas por parte de Fauré (referentes obligados del Art Nouveau) debe haber sido paralelo a su producción gráfica.

Fue así como el trabajo de Fauré durante sus años de juventud le dio el prestigio necesario como para ser reconocido en su rubro y también para tener cierto bienestar económico.

\section{Estación final: Santiago}

Producto de la muerte del padre y que los hermanos hayan contraído matrimonio, la familia Fauré Boyer se disgregó. Ernest Fauré se había casado con Sophie Hemette, también de ascendencia francesa, tenían cinco hijos y estaban radicados en Santiago. Junto a ellos se fueron a vivir Alejandro y Josefina, su madre, con quien tuvo una relación muy cercana hasta la muerte de ella, el año 1910.

La convivencia con la familia Fauré Hemette hizo que Alejandro se convirtiera en un importante referente para sus sobrinos, tanto personal como profesionalmente: les enseñaba a pintar y a dibujar, les hacía teatros de cartón ilustrados con paisajes, los talleres que habían pertenecido a la Imprenta Católica en el centro de la ciudad; dos años más tarde se consolida como un importante negocio.

Dada esta solvencia, se hizo necesario que la imprenta trasladara sus dependencias a un lugar más grande, y así se instala en una sección del edificio de los Padres Agustinos en calle Moneda, también en el centro de la capital chilena.

El personal de la imprenta fue aumentando y ellos mismos describieron su producción de la siguiente manera: "Impresiones en múltiples colores (cromotipia) y con combinaciones elegantes de viñetas; limpias reproducciones de fotograbados y grabados; ediciones correctas y esmeradas de numerosas obras nacionales y preciosas encuadernaciones, he ahí el conjunto de productos, perfectos en su clase, que le han valido a este establecimiento industrial la gran reputación que goza” (Mariano Martínez, 1896).

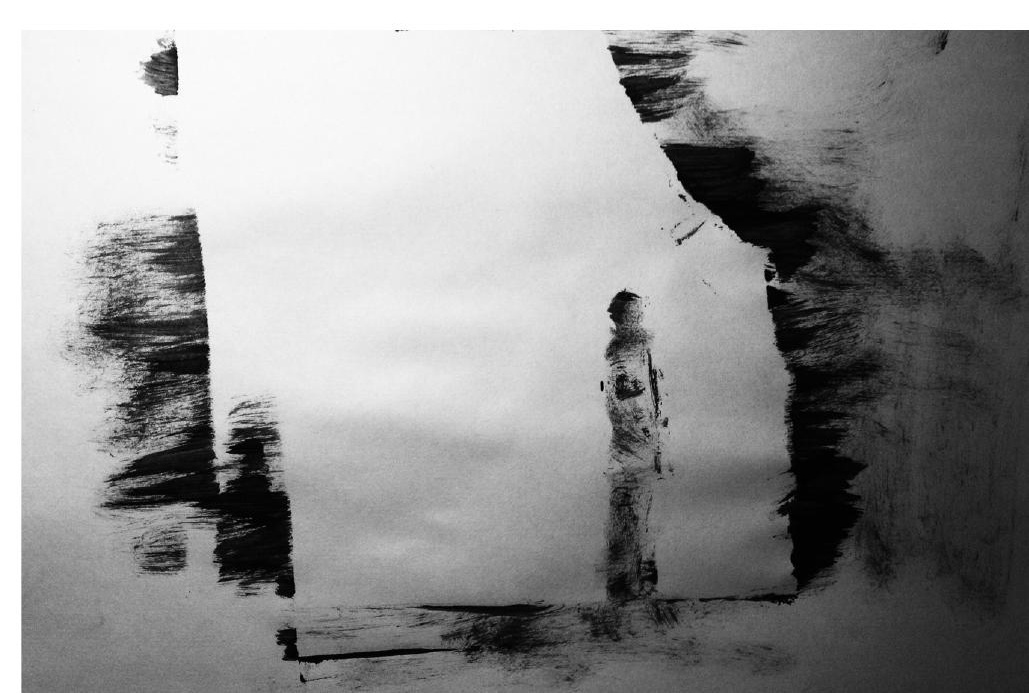


Fauré tenía su estudio en la misma calle Moneda, a un lado del taller de impresión de la Imprenta. Ahí trabajaba solo, pero formaba parte del equipo que tenía a cargo la sección de Litografía de la imprenta; realizaba los dibujos, el transporte a las piedras litográficas, y además sacaba copias de prueba de piezas gráficas, como afiches y documentos valorados, ${ }^{7}$ antes de enviar las matrices al taller. Tenía varios libros con referentes y materia dedicada a las artes gráficas y en sus muros colgaba pruebas de impresión, referentes extranjeros y muestras de trabajos realizados anteriormente. Como pago, Fauré recibía honorarios por cada pieza gráfica realizada.

Sus obras eran reproducidos en litografía, tal como se señaló anteriormente, pero dado lo numeroso de su trabajo, muchas veces necesitó la ayuda de transportadores para copiar las piedras litográficas. Otras veces, sus trabajos eran reproducidos en fotograbado ${ }^{8}$, proceso para el cual constantemente recibió la ayuda de su amigo Julián Ramos, otro obrero gráfico destacado, quien copiaba los dibujos en placas de metal en el taller donde prestaba servicios para diferentes imprentas.

Si en Valparaíso, en sus inicios como artista gráfico, Fauré se dedicó a la producción de etiquetas y envases, en la capital, en la Imprenta Barcelona, se adentró en el mundo editorial como director creativo (referente a los contenidos), como editor artístico (la actual figura del director de arte) y se dedicó a la producción gráfica de portadas para las numerosas revistas que la imprenta editaba, ${ }^{9}$ dibujo de letras y titulares, avisos publicitarios, ilustraciones y viñetas. Julián Ramos lo describe como un profesional muy completo en un artículo que le dedicó en la revista Noticias Gráficas publicada en diciembre de 1912: "era, a más de un gran artista, una verdadera enciclopedia teórico-práctica. El ideaba, dirigía y trabajaba a la vez, conociendo a fondo todos los difíciles y complicados resortes de las Artes Gráficas, debido a su gran constancia y profundos estudios... Obrero infatigable, ambicioso de saber, escudriñaba por entre las hojas de sus libros los procedimientos nuevos y las diferentes escuelas de los maestros europeos... Entre sus trabajos predilectos, tenía verdadero entusiasmo por los grabados al agua fuerte, y los que se hacen sobre acero para la impresión de sellos y billetes de Banco, que él ejecutaba a la pluma a falta de mayores elementos, con una propiedad verdaderamente admirable. De esta forma hizo las muestras que en 1895 se presentaron a S. E. Presidente de la República, para obtener las propuestas que se pidieron en aquella fecha para la impresión en el país de los sellos de Correo y billetes de Banco".

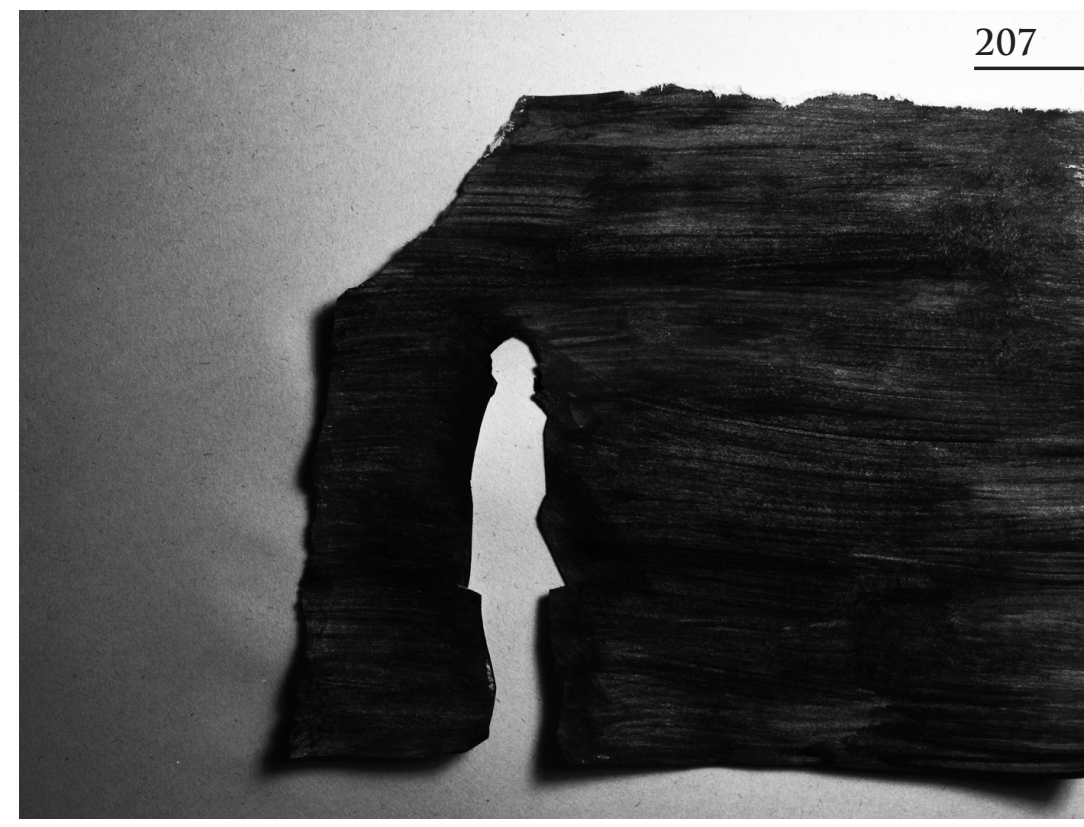

La vasta producción artística y gráfica de Fauré hace suponer que su vida estaba dedicada al trabajo y a la vida en familia, por lo que se sugiere que vivía de manera austera y sus grandes lujos fueran ser parte de la vida bohemia que se había instalado en el mismo barrio de la imprenta. Lamentablemente, poco antes de contraer matrimonio con su prometida durante años, Benigna, Fauré fue informado de padecer una enfermedad incurable. Ante la desesperación, decide poner fin a su vida a los 47 años, el 9 de noviembre de 1912. 


\section{Obra gráfica}

Distinguimos en la obra gráfica de Fauré cuatro líneas dé desarrollo principales: a) ilustración y diseño editorial, b) humor gráfico, c) avisos publicitarios, y d) tipografía y rotulación. Las dos últimas categorías, si bien son herramientas que él supeditó a las dos primeras líneas de desarrollo, se identificaron como independientes dada la vasta producción del artista.

\section{a) Ilustración y diseño editorial}

Alejandro Fauré se especializó en la producción completa de piezas editoriales, específicamente revistas, desde su contenido escrito hasta su ilustración y composición, portadas y encabezados, en el contexto de una naciente industria editorial en el país. Estas publicaciones eran dirigidas a la clase alta y a la naciente clase media, ciudadanos alfabetizados e interesados en informarse acerca de la contingencia y también ser parte de ella. Es importante mencionar en este punto que en Chile "los índices de lectura eran bajísimos. Al finalizar el siglo XIX, un 68\% de la población era analfabeta, cifra que bajara para un 20\% en 1920" (Paula Escobar Chavarría, Cecilia García-Huidobro Mac Auliffe, citando a J. J. Brunner, 2012, pág. 22). Eso explica la importancia de la imagen en la entrega de los mensajes, aspecto que podía producirse mejor gracias a los avances en las técnicas de impresión.

Algunas de las publicaciones más importantes para las que trabajó Fauré fueron:

Pluma y Lápiz: revista semanal que circuló entre los años 1900 y 1904. Fundada por el poeta, periodista y crítico Marcial Cabrera Guerra, buscaba “ofrecer una plataforma de difusión para la escritura literaria, así como una vitrina para la producción de una camada de jóvenes ilustradores que tomaban sus influencias del Art Nouveau y del dibujo cómico" (Pluma y Lápiz, 1900-1904).

Si bien este semanario no tenía en la redacción un equipo estable, se destacó por ser un medio en el que se difundió el trabajo de los escritores jóvenes modernistas y de nuevos fotógrafos e ilustradores. Así, Pluma y Lápiz fue un soporte de intercambio intelectual entre artistas y literatos chilenos, además de contribuir a la difusión de autores extranjeros hasta entonces poco conocidos en nuestro país, como Oscar Wilde o Rubén Darío.

Instantáneas: revista literaria y artística que se publicó semanalmente entre los meses de abril y septiembre de 1900. Al final de este periodo se fusionó con la revista Luz i Sombra, dedicada a las mismas temáticas culturales, y pasa a llamarse Instantáneas de luz i sombra. En una carta dirigida a los periodistas como agradecimiento a la buena acogida de la publicación, escrita por los cerebros tras la revista, Guillermo González Echeñique, Julio Bozo Valenzuela (el caricaturista "Moustache”) y Joaquín Díaz Garcés como su director, Instantáneas se define como un proyecto que "quiere ser sólo el complemento de la prensa diaria, ilustrando con el dibujo o la fotografía lo que en ella no esté ya suficientemente ilustrado con la chispeante nerviosidad de nuestros colegas" (Instantáneas de luz i sombra, 1900-1901). 
Noticias Gráficas: revista que circuló entre los años 1903 y 1939. Publicación mensual, dirigida a la naciente industria de la imprenta en Chile. Era una revista técnica, que entregaba información específica acerca de las últimas novedades para la industria gráfica, desde los insumos y los procesos hasta las máquinas para imprimir y realizar terminaciones. La revista, ilustrada con fotografías y dibujos, era en sí misma un ejemplo de diversas técnicas de impresión en cada uno de sus ejemplares, junto con incluir muestras de nuevos materiales y sustratos.

Fauré destacó, sobre todo, en el desarrollo de la ilustración de sus portadas, las cuales aluden constantemente a una dignificación del oficio del impresor: desde los escribas y tipógrafos, pasando por las bellas artes o el arte más clásico y su producción de obras exclusivas, hasta llegar a la creación de la imprenta por parte de Gutemberg y la valoración de los trabajadores de la industria. La mayoría de las portadas realizadas por Fauré fueron impresas en litografía y fotolitografía (que permitía utilizar tramas de medios tonos más finas que el fotograbado) a 3 colores, sobre papel satinado.

La Ilustración: semanario ilustrado que circuló durante los años 1899 y 1905, encargado de informar temas relacionados con las ciencias, la industria, la educación, la literatura y la música. Con especial preocupación por su visualidad, en esta revista convivían la fotografía y el dibujo, viñetas de humor y retratos. Desde el año 1900 aproximadamente, Alejandro Fauré colabora con ilustraciones, viñetas para la portada, diseño de letras y encabezados.

La Lira Chilena: publicación literaria de los domingos, tal como cita un encabezado de la revista realizado por Fauré, La Lira Chilena fue una publicación santiaguina, semanal, que circuló entre los años 1898 y 1907, lo que la hace acreedora del título de la publicación "más estable y duradera de la transición al siglo XX" (La Lira Chilena, 1898-1907). Esta revista estaba dirigida a las clases más altas y los temas que publicaba estaban relacionados con política nacional e internacional y el mundo cultural. Si en un principio el contenido de estas temáticas era local y algo desestructurado (con especial énfasis y apreciación por todo aquello que tuviera algo francés o inglés), a medida que pasaron los años la revista pasó a tener secciones definidas para un espectro mayor de público: niños, mujeres y hombres de acuerdo a sus ocupaciones o intereses: agricultura, humor, literatura, siendo este último tema el de mayor difusión en las páginas de La Lira Chilena. 
El sitio Memoriachilena.cl, dedicado a la difusión del patrimonio conservado en la Biblioteca Nacional de Santiago de Chile, considera esta publicación una pionera "por las litografías en color realizadas por expertos, por su papel satinado y por el talento y profesionalismo de sus redactores artísticos y dibujantes" (La Lira Chilena, 1898-1907).

Fauré, además de su labor artística, tuvo en La Lira Chilena el cargo de Redactor Artístico, actividad que actualmente se relaciona con la dirección de arte editorial.

Chile Ilustrado: revista mensual que circuló desde el mes de mayo de 1902 hasta los meses de noviembre y diciembre con los números 40 y 41 unidos en una edición. Esta revista era publicada por la Imprenta Barcelona como una manera de responder al público la alta preferencia de sus servicios, al mismo tiempo de dejar testimonio de la superioridad de su trabajo técnico. La línea editorial de esta publicación se enfocaba en presentar los mejores trabajos artísticos y literarios del país y no contaba con una estructura de contenidos definida, sino que más bien dependería del material que les llegara para publicar, según lo dejaron manifestado en la presentación publicada en el primer número de la revista: (Chile Ilustrado, 1902, $\left.\mathrm{n}^{\circ} 1\right)$. "En todos sus números dedicaremos unas cuantas páginas á sintetizar brevemente los tópicos de actualidad de mayor interés público. Además procuraremos amenizarla con trabajos en prosa y poesías selectas de nuestros principales autores. Y, finalmente, en una sección bibliográfica, daremos cuenta de todas las obras de importancia editadas en nuestros talleres".
Fauré realizó diversos trabajos para esta publicación, de lo que destaca especialmente sus portadas, siempre vinculadas a la gráfica victoriana y el Art Nouveau, lo mismo que los encabezados.

\section{b) Humor gráfico}

Si bien los antecedentes del humor gráfico se encuentran en el trabajo de Honoré Daumier, artista francés reconocido por sus caricaturas satíricas, en Chile podríamos decir que el trabajo de Alejandro Fauré también resulta clave en el desarrollo de un humor gráfico con temáticas locales, a pesar de que la técnica y el estilo de su dibujo responden a una tradición más clásica. El mejor y más copioso testimonio que tenemos de ello es la revista El Payaso, una publicación quincenal que costaba 10 centavos y que circuló entre los años 1897 y 1898. Dentro del trabajo realizado por Fauré en esta publicación podemos encontrar: guión para viñetas simples y compuestas (dos o más escenas), ilustración, tipografía ornamental, encabezados, avisos publicitarios y portadas. 
De El Payaso se puede decir que era una revista de entretención: en sus páginas, además del humor gráfico, se podían encontrar adivinanzas, puzzles, problemas de lógica y de matemáticas que los lectores debían solucionar y enviar por escrito a la redacción. Al mismo tiempo, el Payaso era un personaje que contaba en su revista lo que le sucedía, sus pensamientos y reflexiones, cuyo hilo conductor era la contingencia social del momento en la sociedad santiaguina. En el tercer número de la revista, publicado el 28 de noviembre de 1897, el Payaso relata lo siguiente: "por qué he venido tan a menos (aun que yo no sé si sea menos o más esto de ser Payaso) desoyendo los consejos de mi padre que siempre me aconsejaba que fuera serio". Y antes, en la presentación del primer número, publicado el 31 de octubre del mismo año, cuenta como parte de su "programa”: “¿Mis propósitos? Mui sencillo: entretener a Uds. ahora que todo el mundo está triste desde que se ha descubierto la relación directa que hai entre el bolsillo i el ánimo de los individuos.”

En aquellos años, durante la transición del siglo XIX al XX, Chile se encontraba en una buena situación económica gracias a las exportaciones de salitre. Esta entrada de dinero generó un mayor poder de compra, tanto en las clases altas como en la creciente clase media. Ésta última era una clase observadora, testigo de lo que ocurría en los segmentos más altos y más bajos de la sociedad chilena de la época. A ellos pertenecen las nuevas generaciones de artistas y escritores, quienes toman la temperatura a su historia pasada y a su presente, desde una mirada crítica, y las diferencias que antes eran aceptadas y asumidas (como por ejemplo, la relación patrón-campesino), comienzan a ser cuestionadas en esta movilidad social.

Es así como en las viñetas humorísticas de Fauré en El Payaso se puede encontrar esta mirada desde diferentes ángulos, por ejemplo:

Cuestionamiento a los estereotipos sociales: en la portada del primer número de la revista, publicado el 21 de octubre de 1897, el Payaso aparece con su traje de Pierrot, sentado, manipulando marionetas. Estas marionetas corresponden a los estereotipos o personajes que es posible encontrar en la sociedad de la época: bombero, campesino, religiosa, policía, hombre y mujer de clase alta. Dice el Payaso: "Caballeros i Señoritas. Tengo el honor de presentarme ante ustedes con algunos artistas de mi compañía”.

Crítica a la concepción clásica de las Bellas Artes: como se dijo anteriormente, Fauré desde el oficio de artista gráfico nunca fue reconocido como un profesional talentoso en el dibujo o la pintura. La brecha entre las "artes menores" y las "bellas artes" era muy grande, no solamente entre quienes las practicaban, sino también en la sociedad como receptor de aquel trabajo. Por ejemplo, la portada de la revista publicada el 14 de noviembre de 1897 (de la cual salieron 2 ediciones), se ilustró con una viñeta titulada "En el Salón”, donde aparece una pareja de ciudadanos pertenecientes a la clase alta y tienen el siguiente diálogo, a propósito del cuadro que observan:

${ }_{-}$Este es un mamarracho! No merece el premio.

-Pero hijo ¿tú no has mirado el marco que es tan bonito? 
Sátira a la admiración del chileno por lo extranjero, especialmente lo europeo: en la portada de la revista publicada el 12 de diciembre de 1897, se puede ver un par de personajes con las vestimentas típicas del mundo popular. En la viñeta, titulada "Protejido por el encargo aduanero" puede leerse:

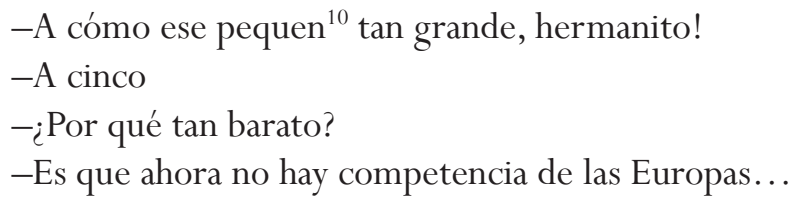

En resumen, el trabajo de Fauré en la revista El Payaso se traduce hoy en una valiosa mirada de lo que estaba ocurriendo en ese momento en Chile, desde una perspectiva cotidiana y alejada del oficialismo.

\section{c) Desarrollo de avisos publicitarios}

Es importante mencionar que el mundo de la publicidad en Chile a fines del siglo XIX y comienzos del XX se desarrollaba de una manera muy distinta de la gran industria que es hoy. Es por este motivo que el trabajo de Fauré no dista demasiado en cuanto a técnica o a los imaginarios que nos presenta en su obra editorial, sin embargo el objetivo de las piezas publicitarias era diferente.

Si bien existían en el medio diversos soportes impresos que eran utilizados para dar a conocer productos y servicios (folletos, avisos en diarios y revistas, afiches y carteles, entre otros) el concepto de imagen corporativa aún no existía ni tenía la relevancia que el mercado le otorga hoy, lo mismo la noción de comunicación estratégica.

Los avances en la tecnología, los medios de transporte y la factura de productos había aumentado las opciones de consumo, al mismo tiempo que la naciente clase media empezaba a tener los medios para acceder a ellos. Este panorama es el que llevó a los dueños de las empresas a tener la necesidad de anunciarse; pero entonces lo importante era aparecer en los medios, ser memorables, destacarse y diferenciarse de los otros productos que se ofrecían en los otros avisos, más bien tipográficos.

La mayor parte de los avisos publicitarios que realizó Fauré tienen una estética Art Nouveau, formas sinuosas y protagonistas femeninas, que al revisarlos en conjunto nos hablan de un imaginario definido, pero no específicamente de los productos que anuncia. Otros trabajos utilizan la figura del cóndor, un ícono importante dentro del imaginario del consumo en nuestro país, sobre todo porque nunca tuvo una personalidad en el mundo comercial sino que continuaba representando la garra y la fortaleza heredadas del águila imperial.

Otro aspecto importante de mencionar es la reutilización de los recursos de producción en imprentas (clichés y planchas con ilustraciones), una práctica muy común que viene desde los inicios de la imprenta en Chile, sobre todo en lo referido a tipos móviles y matrices de ornamentación. 


\section{d) Tipografía y rotulación}

La experticia de Fauré en el dibujo se vio también reflejada en la múltiple cantidad de letras, titulares, alfabetos y encabezados que desarrolló como parte de sus ilustraciones y con los cuales construyó una batería de elementos clave para la composición de piezas gráficas de diversa índole.

Es así como realizó su trabajo con dibujo a lápiz o plumilla, pruebas de impresiones con clichés en diversos soportes (como por ejemplo, cuero), reinterpretó la visualidad con otros medios (por ejemplo, el bordado) e incluso realizó plantillas que permitían reproducir artesanalmente sus alfabetos, más de una vez.

\section{Reflexiones finales}

Para cerrar este artículo sobre Alejandro Fauré como un precursor de la ilustración editorial y el diseño gráfico en Chile y como cronista visual de la sociedad chilena de fines del siglo XIX e inicios del $\mathrm{XX}$, se hace pertinente referirnos a la importancia del período que le tocó vivir como un actor en el desarrollo de una industria editorial y una industria de la imprenta nacional.

La imprenta o las artes gráficas, a mediados del siglo XIX, aún funcionaban en Chile en pequeños talleres artesanales, donde el oficio se aprendía en el trabajo con maestros, quienes entregaban día a día sus conocimientos a los aprendices que entraban a trabajar en esos lugares. En la medida que pasó el tiempo, los obreros gráficos se fueron especializando en cada una de las diferentes etapas de la cadena de producción de la imprenta: fotograbado, transporte, impresión, plisado, encuadernación, etc. y junto a los avances que la técnica iba aportando, los procesos se hacían más rápidos y específicos, hasta que ya entrando al siglo $\mathrm{XX}$ era posible encontrar en el país una industria de la impresión.

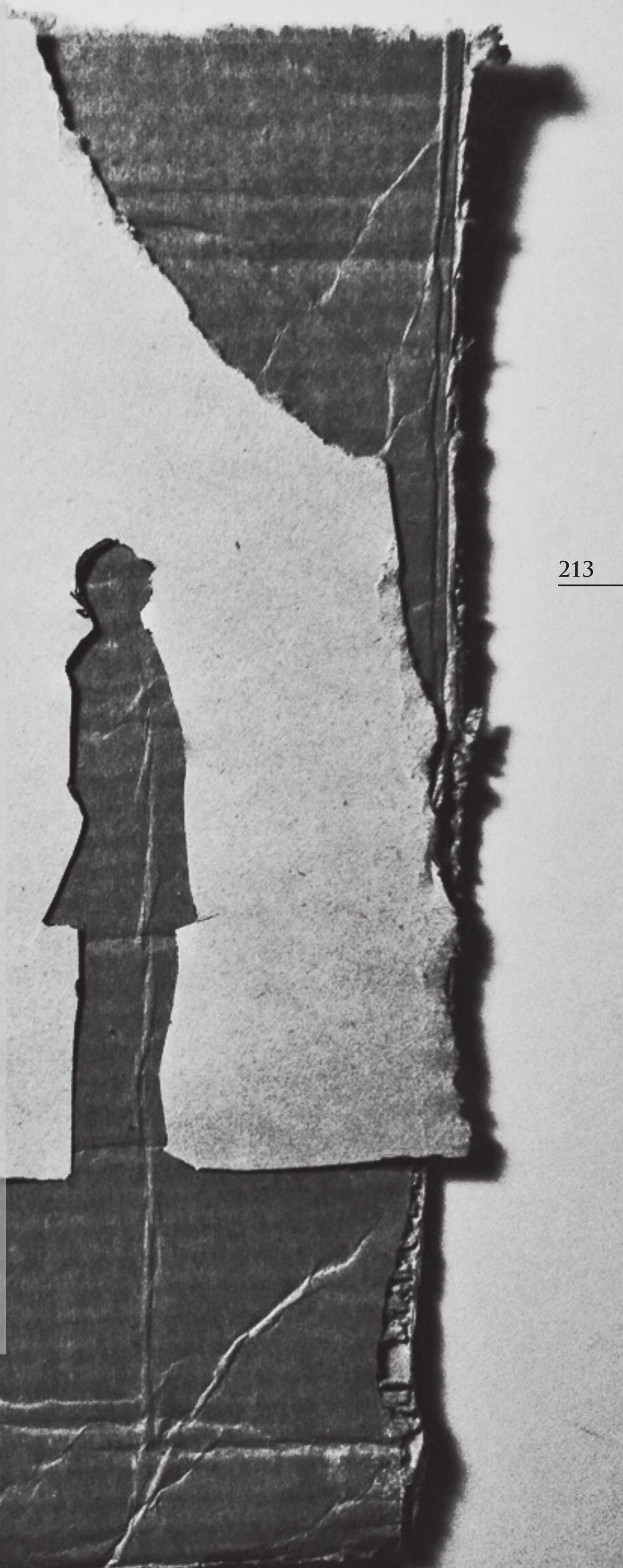


En esos mismos años ya comienza a tomar presencia la figura del editor como un actor relevante $^{11}$ en el desarrollo de la disciplina editorial en nuestro país, pues hasta ese entonces era en las imprentas donde se decidía qué editar y cómo hacerlo. Y, de la misma manera en que el editor se configura como aquel que debe tomar "el conjunto de decisiones que deben hacerse para publicar un libro: elección del texto, elección del formato, elección en cierto sentido de un mercado a través de la publicidad y de la difusión” (Bernardo Subercaseaux, 2010, págs. 104-141), se diferencia también la relevancia y el papel del autor y de la imprenta. Esto último, de acuerdo al positivismo, "la industria y su desarrollo eran temas fundamentales, y constituían una de las vías -junto con la ciencia- que permitirían inscribir al país en la senda del progreso" (Bernardo Subercaseaux, 2010, pág. 131).

\section{Notas}

${ }^{1}$ Ha desarrollado su trabajo de manera independiente en el ámbito editorial en torno a iniciativas patrimoniales, en áreas de investigación que contemplan la historia del diseño gráfico, la comunicación visual y la educación en Chile, al tiempo que se ha especializado en el trabajo con archivos visuales. Coautora del libro Alejandro Fauré, obra gráfica. Monografía de un precursor de la ilustración editorial y el diseño gráfico en Chile (2009, Ocho Libros Editores) y coinvestigadora de Artesanos, Artistas, Artífices. La Escuela de Artes Aplicadas de la Universidad de Chile (2010, Ocho Libros Editores / Pie de Texto).

${ }^{2}$ Socia fundadora de estudio de diseño ff, dedicado al desarrollo de proyectos mayormente ligados al área editorial, cultural y museográfica. Coautora del libro Alejandro Fauré, obra gráfica. Monografía de un precursor de la ilustración editorial y el diseño gráfico en Chile (2009, Ocho Libros Editores).

${ }^{3}$ Sin una planificación estatal, como el caso de la colonia alemana en el sur de Chile, quienes contribuyeron al desarrollo agrícola e industrial del país.

${ }^{4}$ Su nombre proviene de la Reina Victoria, quien gobernó Inglaterra durante los años 1837 y 1910.

${ }^{5}$ El Art Nouveau fue una corriente artística desarrollada en Europa entre fines del siglo XIX y comienzos del XX, inspirada en lo orgánico y la naturaleza.

${ }^{6}$ Una serie de dibujos de Rugendas donde retrata los arquetipos de la sociedad chilena de aquella época, impresos a un color en litografía por Félix Leblanc.

${ }^{7}$ Letras de cambio, billetes, bonos.

${ }^{8}$ Fotograbado: producción de planchas o matrices de metal para impresión, a través de procesos fotográficos.

${ }^{9}$ En aquel entonces aún no se dividía la labor editorial (conceptualización y diseño de los proyectos editoriales) de la imprenta (producción física de los proyectos editoriales).

${ }^{10}$ El pequén es una variante de la empanada, "la empanada de los pobres", rellena de cebolla. Se dice que era la favorita de la destacada folklorista Violeta Parra.

${ }^{11}$ Y que se consolida a mediados del siglo XX. 


\section{Referencias}

Revista Noticias Gráficas (dic. 1912), Santiago de Chile: Editorial Lüer y Paye.

Mariano Martínez (1896), Industrias Santiaguinas, Santiago de Chile:

Imprenta Barcelona.

Paula Escobar Chavarría, Cecilia García-Huidobro Mac Auliffe (2012), Una historia de las revistas chilenas, Santiago de Chile: Ediciones Universidad Diego Portales.

Pluma y Lápiz (1900-1904), Santiago de Chile.

Instantáneas de luz i sombra (1900-1901), Santiago de Chile.

La Lira Chilena (1898-1907), Santiago de Chile.

Chile Ilustrado (1902), Santiago de Chile: Imprenta Barcelona.

Bernardo Subercaseaux (2010), Historia del libro en Chile. Desde la colonia hasta el Bicentenario, Santiago de Chile: Lom Ediciones.

\section{Publicaciones}

Álvarez Caselli, P. (2004). Historia del Diseño Gráfico en Chile. Santiago: Pontificia Universidad Católica de Chile.

Espinoza O., R. (2012). Editado en Chile (1889-2004). Valparaíso: Quilombo Ediciones. García Huidobro, C. y Escobar, P. (2012). Una historia de las revistas chilenas. Santiago: Ediciones Universidad Diego Portales.

Muñoz, M. y Villalobos F. (2009). Alejandro Fauré, obra gráfica. Monografía de un precursor de la ilustración editorial y el diseño gráfico en Chile. Santiago: Ocho Libros Editores.

Subercaseaux, B. (2010). Historia del libro en Chile. Desde la Colonia hasta el Bicentenario. Edición Corregida, aumentada e ilustrada. Santiago: LOM Ediciones.

\section{Web}

www.memoriachilena.cl

Recibido: octubre 30 / Aprobado: noviembre 28 de 2013

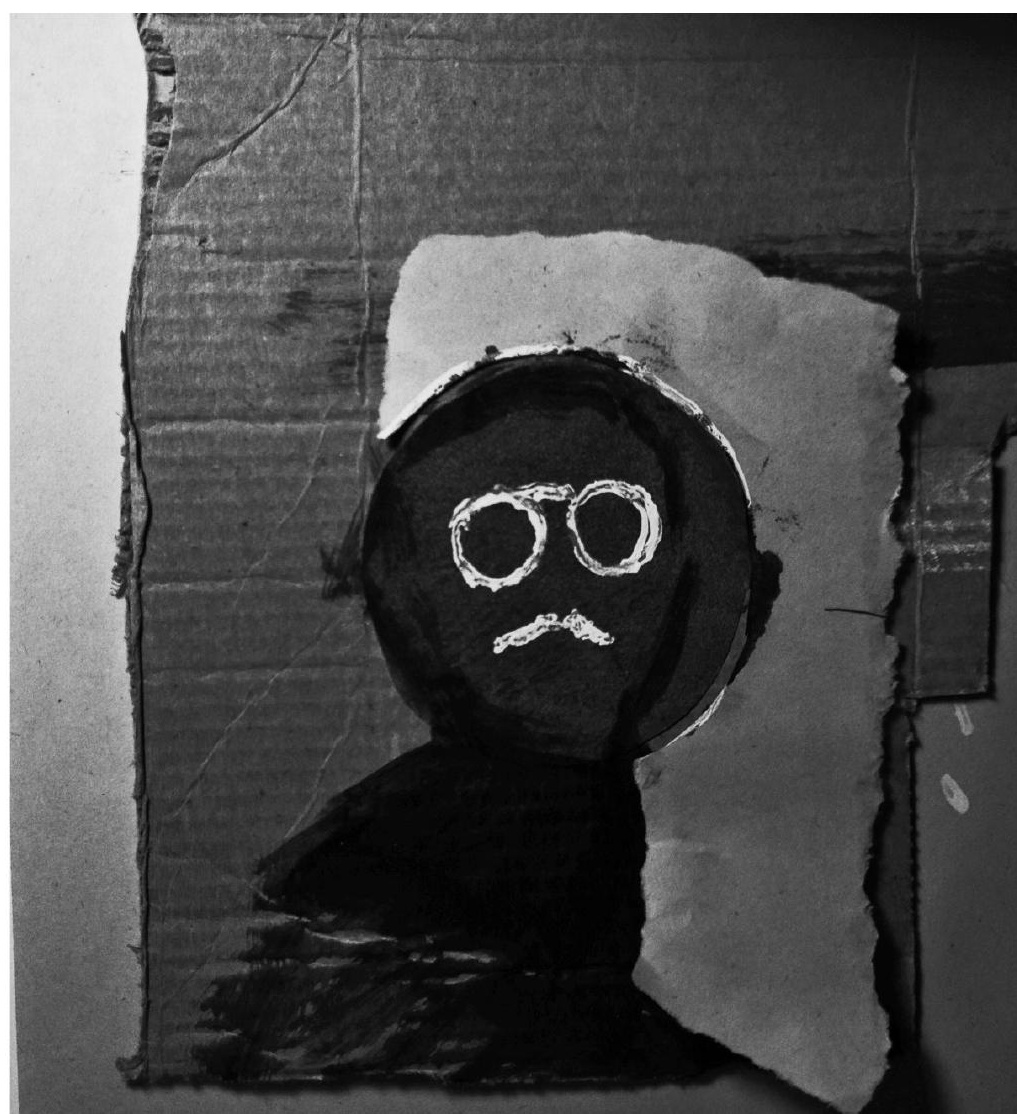

